\title{
EDUCATIONAL
}

TECHNOLOGY

\section{Microcomputers and education}

\author{
Alex Maggs, Ph.D. \\ School of Education, Macquarie University \\ Elaine Ray, B.Sc. (Hons) Dip.Ed. \\ BIS-Shrapnel Pty. Ltd.
}

\section{Introduction}

Microcomputers in education is a new area of development; and computer literacy is the basic skill of the 1980s. To the extent that the mechanical age revolutionised our lives, computers have the potential to restructure our schools.

\section{How will this affect children?}

Will the Federal and State government departments meet the challenges of the electronics age, or will teachers and teacher training institutions leave it to the computer industry to develop, produce and market the myriad electronic teaching devices that will flood the market in the 1980s?

Microprocessors already impinge daily on the lives of most Australians. They control an ever increasing range of both products and services, from our watches and calculators to our routine banking transactions. More and more they are becoming so important both directly and indirectly, in our lives that we cannot help but become aware as they rampage through the later part of the 20th century with their far-reaching social and economics implications. It is the responsibility of all educators and policy makers to prepare students with a sound body of skills and understanding of computers and computer literacy in order that they will be able to fit into an increasingly technological workforce.

Everybody has heard of the silicon chip, the media is often full of sensational claims concerning chips and how they will transform our lives - for better or for worse. The potential of the chip and the microelectronics revolution is enormous - we cannot afford to ignore it or sweep it under the carpet in the hope that it will go away. We must come to terms with and understand chips their capabilities and their limitations - are they good or bad - will they provide a panacea for the ills of the world, take the drudgery out of production and domestic chores or just cause massive unemployment? It is already the eleventh year of the Age of Information (as this new technological era has been termed), and within the next eleven we are likely to witness drastic changes in the economic and social structure of western civilization as we now know it. The chip will affect everybody: at home, at work, in 
education, medicine, communications, crime, defence and security. Within this time approximately half of today's jobs will change drastically, or disappear altogether to be replaced by the new technology; robots are already taking over assembly line jobs from blue collar workers. microelectronic devices are transforming white collar employment. The chip will usher in the miracles and miseries of the Age of Information.

In the same manner as the Enclosures Acts were a catalyst in forcing people from an agrarian to an industrial based workforce, so will the technological revolution force more and more people to seek employment directly related to the new technology. People are concerned as to which jobs will disappear, to what extent will they be able to seek re-employment in newly emerging positions, will they have the necessary education and skills, will they be able to enjoy the promised new found leisure time - confident that they have economic security to do so?

Computers are here to stay, they have arrived virtually through the back doors of industry and commerce, their technology must be harnessed to prepare students to live and interact in the Age of Information.

\section{In the beginning}

Since the beginning of civilization mankind has constantly sought ways in which to improve his mechanical and intellectual power. In this constant search through the ages, civilization has developed from a group of nomadic cave dwellers to the highly structured urban society that we are all familiar with. This progression has come hand in hand with tremendous technological change, from the invention of the wheel to the silicon chip. With these changes in technology and lifestyle mankind has also evolved a complex education system that facilitates society to obtain a maximum benefit from new discoveries and integrates human endeavour into a gainful productivity that is utilised by society as a whole.

The evolution of computer technology has been just another tool to provide mankind with an extension of thought patterns and solutions to problems. The electronics industry evolved from the first valve to the first transistor in a period of 50 years. Phenomenal expansion followed the introduction of transistors in 1948. Integrated circuits, combinations of transistors and semi_conductors (substances such as silicon and germanium) developed during the late 1950s, reduced size, cost and electrical drain on the huge mainframe computers that were first produced during the 1940s and 1950s. The flow of electricity could be controlled much more accurately and computing power became economically viable. In 1940 it was estimated that the number of applications for computers would total 100 installations worldwide, be operated by a small number of highly trained technocrats, and be used exclusively by governments. Today, nobody would be brave enough to estimate either numbers of computers required, people to operate them, or the applications to which they might be put. The potential of the silicon chip is almost beyond comprehension and already we are being catapulted into an Orwellian world where fact is now stranger than fiction.

\section{1 - The beginning of the age of information}

In the same manner as the Industrial Revolution was said to have started with Watt and Stevenson and the inauguration of Britain's first railway in 1830, the 
Age of Information began in 1971 with the creation of the first single chip microprocessor by the Intel Corporation of Silicon Valley in California. Intel Corporation was founded in 1968 by Gordon Moore and Robert Noyce - both pioneers in the development of transistors, and 12 employees. Silicon Valley was originally an orchard area in Sunnyvale, located at the southern end of the San Francisco Bay. The name Silicon Valley is derived from the principal product of the semiconductor industry - complex electronic circuits build on pieces of silicon the size of the thumbnail. Today Intel is one of the world's largest manufacturers of chips and Silicon Valley a huge industrial hinterland employing thousands of the new generation workers that set the standards that control the development of the world's technology. The figures below indicate the number of transistors which fit on a chip of silicon about half a centimeter square and provide a graphic indication as to just what is meant by miniaturisation:

1960 one

1970 one thousand

1980 one million

These figures, while not only impressive in size and performance, were accompanied by a decrease in cost and an increase in computing power - the beginning of the microelectronic revolution. In terms of relating these figures to something that we are all familiar with it is worth considering two products that we take very much for granted today - an electronic calculator and a digital watch. In the early 1970 s both these products cost in the order of $\$ 2,000$ and were thus available to a very small portion of the population. In the past years and despite inflation, it is now possible for everybody to buy them for about $\$ 10$ and dispose of them when they break down. The microelectronics revolution in terms that we can all comprehend, but how many of us comprehend that exactly the same thing is happening in the computer industry.

\section{Microelectronics and the future}

While the technological revolution has created new industries and jobs, it has also brought about wholesale elimination of selected crafts and professions. An industry that best illustrates this point is the printing industry. Up to the early 1970s printing had changed little since Gutenburg - all printed media had to be produced by a labour intensive method of individual letters, linotype machines manned by an army of tradesmen and operators, and very long production times. Today phototypesetters connected directly to wordprocessing terminals can be operated by a typist and journalist Writing, editing, composition, layout and pagination can be produced on the one machine in a matter of minutes. Phototype and bromides replace the individually selected letters embedded in lead and production time is at least $200 \%$ faster than traditional lithotype methods. This leaves the linotype tradesman as antiquated as the wheelwright.

Technological change has always been creating and eliminating jobs but, for the very first time, machines can now compete with humans for jobs that are dependent on intelligence.

Today, microelectronics does not rival the human brain but this is not necessary before it starts replacing people. While many jobs, especially production and assembly jobs, make little use of human intelligence, 
technological advances have heralded the introduction of microelectronically controlled robots that can be programmed to perform specific repetitious tasks. Robots coming off production lines in Japan today can even see and hear to a limited extent and the Japanese NEC Corporation has already began to advertise a secretary robot which can get people on the telephone and perform routine secretarial functions. Japan leads the world in the manufacture and use of industrial robots with more than half the world's total installed in Japanese factories. This total is something in the order of 50,000 robots of all kinds working in factories in 1980, compared with 6,000 installed in West Germany and 4,000 in the U.S.A. (Industrial Robot Association of Japan, 1980). It is also interesting to note that Japan and West Germany lead the world with the introduction of computer literacy in education and have a complex system of technological and associated education.

To industry that is besieged by inflation, the necessity of increasing production, lack of skilled workers and growing union demands, robots provide a very attractive alternative to humans. Not only do they stay on the job, they require no tea breaks, or holiday pay; they will work in almost any conditions and don't suffer from hangovers, or organise into unions. Once the initial capital outlay has been made they require very little service or maintenance. One robot may replace 10 people on a production line, but it may only take one service engineer to keep it functional. Robots are already occupying a growing place in the assembly of automobiles, and in Japan robots are being used to assemble other robots. As robots are integrated into assembly lines on a large scale their impact on the blue collar workforce will be far reaching. This is likely to be more pronounced in western countries where there has been a tradition of suspicion to automation and the introduction of automation is usually traded off with the unions being given some sort of sweetheart agreement to soften the blow. This is in direct contrast to Japan where workers in the biggest companies are often lifelong employees and feel very close ties to their company and its profit structure. There robots are welcomed not as a job threat but as a 'fellow worker' which will help improve productivity.

Given that up to $25 \%$ of today's workforce has assembly line jobs, $90 \%$ of these jobs could be eliminated over the next 20 years. The social and political implications of such changes could well change western democracies. Unions are unlikely to stand back and let this go unchallenged. Questions of law and order arise - will workers turn on this new technology and smash equipment in the manner as they turned on the French inventor Joseph Hacquard when he invented the Jacquard Loom in 1801? On the positive side, microelectronics could feasibly eliminate up to half the labour costs involved in the manufacture of consumer durables and provided the blue collar workforce was suitably educated, it could find new avenues of employment as industry changes to meet growing demands, e.g. instructional and software designers, television and video industries, defence, etc.

The white collar workforce is likely to feel the threat of technology in their employment much earlier than their blue collar counterparts. Computers, terminals, communication devices and printers are familiar in almost every office, streamlining routine operations and increasing productivity. To date the white collar has little to fear of office automation - fear and worship often go hand in hand in a love/hate relationship with computer technology Everyone is content when a million invoices are produced and posted on time but imagine the drama if every one of these invoices was incorrect due to a 
slight programming error! It is a matter of expediency for management to sack the programmer and blame the computer. Society has already been conditioned to accept the faults and failings of computers without even questioning why or how. Very few comprehend that a computer does not have an 'ego' or a brain, it is just a machine that relies on human input in the form of a program to instruct it in a very rigid sequential logic.

\section{Education - the future}

Most people relate to technological change purely in the light of as to how it affects their employment, with education providing the key to the ability of individuals to accept and be accommodated by changes that are already very much apparent in the workforce.

As the development and application of microprocessor technology shows no sign of slowing down, we are already feeling the effects in work, the home, and the school. On the domestic level we expect more and more labour saving appliances to invade our lives and titillate our expectations. In the school arena this invasion is seen to be more ominous and threatening. The huge number of unemployed youth must in itself bear witness to the changing technology and government inability to cope with it.

It is estimated that as many as $90 \%$ of students will pass out of high schools in Australia at the end of 1982 without ever having seen a microcomputer in a meaningful context, let alone had the experience of understanding how it works or 'hands on' control. Just how the schools are endeavouring to meet the challenges of the 1980s appears to be very nebulous to say the least, and one could almost assume that the changes, slow as they are, are occurring almost despite the obvious limitations of the present education system and a lack of funding.

Teachers have a clear responsibility towards their students. However, teachers en masse, are very much more concerned with the immediate question of how computer technology will affect their status; and will in due course, the students sit in their own homes with their terminals, learning at their own pace and thus superseding schools and teachers altogether.

Irresponsible speculation of this nature can only help but keep education in computer literacy out of schools and ignore a rapidly changing world. Properly used, the microcomputer has the potential to become a very powerful administrative and teaching aid, capable of enhancing the education experience of all students in a range of subjects from the very obvious mathematics / science usage through to art, music and host of other disciplines. Computers will never replace teachers in the classroom, only provide yet another means of educating young people to fit into the Age of Information with confidence and knowledge.

\section{Today - microcomputers in the classroom}

The world once saw a gradual transition from illiteracy to literacy, from centuries when only a elite few could read or write, to a time of international recognition of the right of every child to an education. The computer age, far from being a potential evolution, has already been thrust upon us. Like every technological advance, the computer is a tool responsive to our decisions. Whether we allow it, by default, to restrict or determine our lives, or use its 
potential to enrich and broaden our options, will depend primarily on our approach to computer education.

Thousands of children, leaving school this year, still live in a world where almost every aspect of their home and working lives, will involve some form of computerisation. Yet, almost none of these school-leavers will have learned about computers and their operation, let alone have had a sound training in computer program design. Even less comprehensibly, in an age where classroom research and programs have made basic literacy and numeracy available to even severely retarded children, thousands of bright schoolleavers lack the adequate skills in reading, writing, spelling and numeracy required to deal with our present complex society. Yet, dealing effectively with computers, will require even more advanced and reasoning skills.

Computers and education are not, of course, a novel marriage. But their role has primarily been one of computer assisted instruction (CAI) or computer managed instruction (CMI). In assisted instruction, students are taught by the computer. It presents material, allows practice, tests the students' learning, and gives their results. If necessary, it follows up with further repetition of material where errors were made, and further opportunities for practice. In computer managed instruction the massive amount of information that can accumulate about students can be organised onto computer for easy recall; test data cannot only be quantified but analysed for the type of diagnostic detail and resultant programming requirements that overworked school counsellors find difficult to do; evaluation of the teacher's instruction and the students' progress is handled by the computer. But neither two approaches puts the student in control; he has scarcely to know how the computer operates (as opposed to knowing which button to push) let alone have any mastery of programming principles.

\section{Direct instruction microcomputing - methodology for the $80 \mathrm{~s}$}

Direct instruction microcomputing (Cross, Hermann, Maggs and Maggs, 1982) is based on the right of the student (and his teacher) to be truly literate in his understanding of computers and his ability to design programs for them. Direct instruction principles and practices come in at three different levels:

1. teaching the initial required skills for computer education secure skills in reading, spelling, numeracy, written expression, and logical reasoning;

2. the instructional design of computer education programs; and

3. the actual classroom teaching of microcomputer program skills.

During 1981, an Education Research and Development Committee (ERDC) grant was provided for the study of learning outcomes and academic engaged time in the area of direct instruction and microcomputing. Ten regular schools, (seven independent and three government) were involved in the research project. A total of 800 grade 5 and grade 6 children, both male and female, participated in the project (Gelder and Maggs 1982).

A thorough examination of the Direct Instruction model across a number of research studies and programs of instruction elicited four key variables. These variables, structure of teacher presentation, programming of the content area (i.e. microcomputing design), teacher supervision and the format of written materials were experimentally manipulated. The design of the four methods of instruction ranged from high to low structure on the key variables. 
A post test was administered to all children. Analysis of variance revealed that there were no significant differences between methods across schools. However, there were significant differences between schools on both individual items and the total number of items correct. The differences between schools indicated that children attending independent schools achieved higher post test scores than those attending the government schools.

Discriminant analyses were undertaken to examine the interaction between school type (i.e. independent or government) and the four methods. The results revealed that when the high structured Direct Instruction model was implemented across schools there were no significant differences. Hence irrespective of whether schools were independent or government, the high structured method was the most successful. In addition, on the least structured method, independent schools performed significantly higher than government schools.

A further study teaching microcomputing design skills using the high structure of Direct Instruction was conducted at a residential institution with the mentally retarded. Field studies using Direct Instruction programs have shown that developmentally disabled children can inductively learn basic intellectual behaviours, acquire competencies in basic numeracy and literacy and exhibit the acquisition of cognitive processes by generalising the concepts learned to tests of general cognitive functioning (Gersten \& Maggs, in press). The purpose of this study was to examine whether the subjects could generalise the concepts learned in the microcomputing design area. After fifteen weeks of instruction, the results revealed that these skills were well within reach of the adolescents who participated in this research study (Berryman \& Maggs, 1982).

\section{The instructional design of computer education programs}

There is a serious risk that computer education will repeat many of the errors of the last decade's schooling. There have already been studies indicating that Computer Assisted Instruction in the way it was being used, was not as effective as even conventional teaching techniques. Approaches to teaching children to program computers have followed the popular wisdom of such unsubstantial approaches as "language experience" or "discovery learning" Computer education, as new as it is, has the opportunity to build on the crest of education research.

We know there are critical direct instruction components of instructional design. These need more than a simplistic explanation but, briefly, include:

1. Generalisation. When we design a computer program, a reading or a maths program, generalisation is a critical component. It will be even more critical in programs we design to teach children how to develop their own computer programs. Very simply this ensures that our program teaches by rules and reasoning instead of rote learning; that a small amount of learning will generate disproportionately large areas of self-generated new learning. Instead of teaching thousands of facts, a few of those facts would be taught with the critical rules and discriminations to allow the student to work out the thousands of other facts for himself. This allows an economy of teaching that is critical in today's information explosion. 
2. A presentation consistent with only one interpretation. Few teaching presentations are as clear and unambiguous as the teacher thinks they are. The child may even be concentrating on the accidental red smudge on the card instead of the little black triangle the teacher thinks he is looking at. Verbal instruction becomes even more complex and allows for more instructional misinterpretations. If computer programming instruction is not as unambiguous as direct instruction design principles can make it, we will end up with the same learning patterns as in other basic skills: most very bright children will succeed, many bright children will fail, and those already vulnerable to learning difficulties will add a new set of failures.

3. Teaching more in less time. One major element in research findings on effective programming has been the concept of "academic engaged time". Most assumptions that children are actively engaged in learning are simply that - assumptions. It has been found to be essential that any program design should give constant and immediate feedback to the teacher that the child is indeed academically engaged and giving correct responses.Teaching more in less time is the only way the same period of schooling can cover more skills and more advanced learning in our rapidly advancing society; increasing the amount of academic engaged time the program design calls for is one way of achieving this.

4. A range of other factors come into direct instruction program principles. These include aiding memory and reducing interference; adequate practice of new learning; the opportunity to review critical earlier work; preteaching those skills required for success in later programming stages; with all these elements supporting the ultimate task of developing the cognitive structures in our computer program are simple ways of organising information to provide strategies for solving problems.

\section{Research and development}

The computer is unique from other education media because of its ability to have dialogue with the student. Computers are a tool for thinking, but can only be utilised properly by control from the teachers. Teachers control computers, not vice versa. The teacher using properly structured and sequenced techniques, uses the computer to present material to students, students learn it, the computer tests, students respond and the computer provides instantaneous feedback. One of the main ways computers are used in the real world is as simulators. Simulations allow students to pick out models of problems and solutions. Through simulation, the computer becomes a tool for that "real world" built into school curriculum.

Computers should be used as adjuncts, as another instructional technique. It has never been suggested (despite teachers' fears) that teachers just abandon children to equipment - this is why it is so important to have professionally qualified teachers involved in developing instructional methodology and software; to ensure that the computer is appropriately used and integrated into a total education program.

Some of the research issues that need to be investigated in the area of microcomputers and education are: 
1. What should the role of microcomputers in education involve, especially in the service delivery of education?

2. What are effective methods in training teachers as instructional designers so that they can design appropriate microcomputing programs for school and classroom usage?

3. Can the majority of Australian children and adults benefit from appropriate microcomputing courses?

4. What are the effective ways of utilising powerful varied microcomputers?

5. How can parent of children help at home in developing computer literacy skills?

6. What standards need to be set for hardware, software and communications in the utilisation of microcomputers, particularly in education?

7. Should computer technology involve a centralised or decentralised mini / main frame computer with a large educational data base that can be assessed by all schools?

8. How can information on careers in computer technology and associated employment be disseminated to all Australian school students?

9. What are the responsibilities of the computer industry to the field of education in Australia?

10. How can "disadvantaged" groups of children, e.g. isolated children in the country be assured of the same opportunities in microcomputer technology education?

\section{Changing directions}

One could hardly be accused of cynicism in observing that the Federal Government would appear to maintain almost a vested interest in stifling debate and resisting change. Change costs money. Very little has been done on an official level to implement broad programs that will change the traditional structure of education establishments and make them more aware of their responsibility to provide meaningful courses for teachers and students. The age old questions of tenure and tradition, coupled with the inevitable subject jealousies arise. One very obvious answer is that computers can be used over a wide range of subjects. Another is that large scale production of computerbased curriculum will require a large number of teachers to implement it. In the future many teachers will shift from being deliverers of courses to being designers and developers of materials.

However, despite the problems of tradition, lack of knowledge, suspicion, resistance, and real lack of funding a growing number of microcomputers are finding their way into Australian schools, both at the primary and secondary levels. This number is expected to rapidly increase over the next two years probably to the stage where the small portable microcomputer is as numerous as the overhead projector or the ubiquitous Fordigraph duplicating machine. Growing awareness of educators coupled with an effective cost reduction in microcomputer hardware will put these educational devices within the reach of most schools - probably through parent action and financial backing. Parents are constantly concerned with the quality of education that their children are receiving and the relevancy of education to equip them for employment. Due to parents placing top priority on computer literacy, it has often been the lot of parent-teacher associations to raise the necessary funds required to place microcomputers in the various schools. 
All these changes will come about almost despite government and the system. In Australia, where there is no central co-ordinated pattern or policy governing direction, implementation or enhancement of education on a national scale, huge problems exist. The Federal government has traditionally left all matters of syllabus development, teacher training, and immediate funding of educational establishments to the individual states. This policy (or lack of) is fraught with pitfalls - how can the government commission the Myers Report and pay lip service to its far reaching findings and yet not even consider (to date) a concerted effort to bring about computer literacy to every Australian child from age five onwards?

The government must prepare to become totally committed, both in terms of policy and more importantly funding, to providing a viable future to young Australians. Computers are here to stay and already they are causing waves and rocking the traditional structures of society. Computer technology must be harnessed to prepare students to live and interact with technology. Computer literacy should become as important in school curriculum as the traditional reading, writing and arithmetic.

Computers have been used for over a decade by Universities and Colleges of Advanced and Technical Education in the specific disciplines of computer science, data processing, mathematics and physics. With the tremendous changes in technology and the introduction of commercially available low-cost microcomputers in the late 1970s computers in education are no longer a source of speculation, science fiction, or wonderment. They are here, available, ready for use and it is up to the relevant authorities to be aware and implement their integration into school curriculum as rapidly as possible, from infants level to high school and beyond.

As a medium for expressing, manipulating and communicating ideas, the computer could equal the power and impact of the printing press.

\section{References}

Berryman, D. \& Maggs, A. (1982). Direct Instruction Microcomputing with Developmentally Disabled Institutionalised Adolescents. Unpublished Manuscript, Macquarie University.

Cross, M., Hermann, G., Maggs, A. \& Maggs, R. (1982). Microcomputing skills: A direct instruction approach. Unpublished Manuscript, Macquarie University.

Gelder, A. \& Maggs, A. (1982). Academic engaged time, learning gains and direct instruction in microcomputing program design skill development. Unpublished Manuscript, Macquarie University.

Gersten, R. \& Maggs, A. Teaching the General Case to Moderately and Severely Retarded Children: A Five Year Study. Analysis and Intervention in Developmental Disabilities. (in press)

Please cite as: Maggs, A. and Ray, E. (1985). Microcomputers and education. Australian Journal of Educational Technology, 1(1), 2-11. http:/ / www.ascilite.org.au / ajet/ajet1/maggs.html 